\title{
LA REVOLUCIÓN CONSTITUCIONAL EN CÁDIZ A TRAVÉS DE LOS DECRETOS DE CORTES
}

\author{
ASUNCIÓN DE LA IGLESIA CHAMARRO
}




\section{SUMARIO}

1. CONSIDERACIONES PRELIMINARES. 2. EL DECRETO COMO INSTRUMENTO VINCULADO HISTÓRICAMENTE A LA POTESTAD SUPREMA. 2.1. De los derechos a los reales decretos. 2.2. Los decretos por doquier en el contexto que precede a la reunión de las Cortes de Cádiz. 3. LOS DECRETOS ASAMBLEARIOS EN LA REVOLUCIÓN FRANCESA COMO FUENTE EXPRESIVA DE LA REVOLUCIÓN MISMA. 4. LOS DECRETOS DE LAS CORTES DE CÁDIZ. 4.1. Las Cortes Generales y Extraordinarias y la plenitud de poder. 4.2. Los principales Decretos de las Cortes Generales y Extraordinarias. Contenido y forma. 4.3. Los Decretos de Cortes tras la aprobación de la Constitución de 1812. La distinción entre Leyes y Decretos de Cortes. 


\title{
LA REVOLUCIÓN CONSTITUCIONAL EN CÁDIZ A TRAVÉS DE LOS DECRETOS DE CORTES*
}

\author{
POR \\ ASUNCIÓN DE LA IGLESIA CHAMARRO \\ Universidad de Navarra
}

\section{CONSIDERACIONES PRELIMINARES}

El poder político, en la medida en que es poder jurídico, se manifiesta a través de las fuentes del Derecho entendidas como instrumentos dispositivos por los que se transmite la vis del Derecho, sean reglas o resoluciones concretas. Con su nomen iuris y su modo propio de exteriorización, un instrumento dispositivo ${ }^{1}$ da cuenta del titular que expresa su voluntad y del poder que ostenta; es indicativo

* El presente trabajo se enmarca dentro del proyecto de investigación «La prehistoria del Derecho Constitucional» (DER2009-11050) financiado por el Ministerio de Ciencia e Innovación.

${ }^{1}$ Es conocida la dificultad para definir con precisión qué deba entenderse por fuentes del Derecho y la diversidad de sentidos con que se emplea la expresión. Así, DE Отто señala que, por una parte, «el derecho mana o procede de un conglomerado informe de factores que van desde las simples circunstancias fácticas, incluso no humanas, hasta conductas minuciosamente regladas por el ordenamiento» y la pregunta acerca de las fuentes lleva — para este autor - tanto a las «situaciones o circunstancias de hecho que explican por qué y para qué la norma se dictó», y, por otra parte, el poder que interviene en la creación de las normas manifiesta «la voluntad normadora del órgano habilitado por el ordenamiento jurídico que le atribuye la virtualidad de producir una norma jurídica». De Otто, I. (1993). Derecho Constitucional. Sistema de fuentes. $3^{\mathrm{a}}$ reimp, Ariel, Barcelona, pág. 70. Por mi parte, para evitar el problema de la diversidad de sentidos de la expresión «fuentes del derecho» hablaré de instrumento dispositivo, más cuando en este periodo de declive del Antiguo Régimen y alumbramiento del Estado constitucional no existe aún previsibilidad en el propio ordenamiento jurídico de los modos de producción normativa. 
— normalmente - de un procedimiento de elaboración, y responde — si lo hay - a un determinado modelo de distribución de potestades normativas. Por eso, los cambios en los regímenes políticos tienen su correlato en los instrumentos dispositivos, que se crean, modifican o renuevan en su significado.

Una manifestación clara de lo anterior se da precisamente en el periodo de la revolución constitucional de las Cortes de Cádiz. Piénsese que frente a los modos de creación del Derecho del Antiguo Régimen, la afirmación del principio de división de poderes trastocará el sistema de producción dispositiva. En una primera fase de gobierno asambleario el Decreto de Cortes tendrá un papel protagonista y será el modo de expresión de los principales acuerdos. Después, en el texto constitucional de 1812, Decreto y Ley indicarán, respectivamente, las disposiciones y resoluciones que las Cortes adoptan con plena potestad y aquellas en las que se precisa la sanción regia, sin que aún se pueda ver con suficiente nitidez —al menos en los textos - un concepto material de ley. Con el tiempo, el modelo será la fragua de los conceptos de ley y de reserva de ley y la potestad ejecutiva se concretará, en parte, en el reconocimiento de la potestad reglamentaria ${ }^{2}$.

Dentro de este contexto revolucionario del sistema jurídico político merecen una atención particular los Decretos de las Cortes Generales y Extraordinarias. A través de ellos España se abrió al constitucionalismo, intentó una transformación social en numerosas cuestiones y se aventuró a «levantar una nueva estructura jurídico política del Estado» ${ }^{3}$. Así, por Decreto de Cortes se proclamaron la soberanía nacional y el principio de división de poderes (D. 24 de septiembre de 1808), la igualdad de derechos entre los españoles europeos y ultramarinos (15 de octubre de 1810), la libertad de imprenta (D.10 de noviembre de 1810) o, en fin, se abolió de la pena de horca (el 24 de enero de 1812).

Aparte del indudable interés del contenido, los Decretos de Cortes son «una excepcional originalidad del Derecho Constitucional español» ${ }^{5}$ y constituyen en sí

2 Vid. Gallego Anabitarte, A. (1971). Ley y reglamento en el Derecho Público occidental. Instituto de Estudios Administrativos. Madrid, pág. 172 y ss. Marcuello Benedicto, J. I. (1996). «División de poderes y proceso legislativo en el sistema constitucional de 1812». Revista de Estudios Políticos. núm. 93, págs. 219 y ss.

3 Pons Irazazábal, F, y De Carvajal, J. F. (1987), en la presentación a la edición facsímil de la Colección de decretos y órdenes de las Cortes de Cádiz. Congreso de los Diputados. Madrid. La colección original se publicó bajo el título Colección de los Decretos y Órdenes que han expedido las Cortes Generales y Extraordinarias desde su instalación. Imprenta real, Cádiz 1811-1813.

${ }^{4}$ Al final de este texto incluyo como anexo una selección hecha de entre los más de 300 decretos que aprobaron las Cortes gaditanas atendiendo a su interés constitucional o su relevancia política.

${ }^{5}$ Es curioso cómo a pesar de lo extraordinario de esta figura no ha sido objeto de atención suficiente por la doctrina. Como excepción Gallego AnAbitarte, A. en su trabajo ya citado en el 
mismos una manifestación muy elocuente de la revolución misma, pues son reflejo de la transferencia de la soberanía del Monarca a la Nación representada en las Cortes. En efecto, el decreto asambleario fue el modo de expresión jurídica de la soberanía ${ }^{6}$ de las Cortes de Cádiz desde 1810 a 1813 y también por Decreto se dictaron disposiciones generales, de eficacia jurisdiccional o de gobierno ordinario ${ }^{7}$.

$\mathrm{Y}$ es que en este ínterin revolucionario y constituyente los procedimientos se improvisan. La aplicación del principio división de poderes está aún en fase embrionaria ${ }^{8}$ y poco más que de su proclamación puede hablarse, pues la desconfianza hacia el rey y el Ejecutivo — representado en el Consejo de Regencia- llevarán a las Cortes a ejercer el poder con plenitud ${ }^{9}$ constituyendo un modelo de gobierno de asamblea ${ }^{10}$. Por eso se puede decir sin matices que en la revolución constitucional gaditana el poder constituyente y la soberanía, la

que hace notar cómo «esta excepcional originalidad del Derecho constitucional español, cuyo rastro se puede seguir hasta nuestros días, ha queda ignorada y desconocida, por un «dualístico» y absurdo aparato categorial que para hacer ser valer ha mal interpretado los textos (...), y no los ha dejado hablar en su riqueza institucional bajo el férreo peso del dogmatismo». Vid. Gallego Anabitarte, A. (1971): pág. 172. Por otra parte, encontramos decretos de Cortes entre 18101812, 1820-1823, 1826-1837 o, incluso en 1931, cuando las Cortes Constituyente de la II República nombraron así Presidente del Gobierno ante la ausencia de titular de la Jefatura del Estado: «Las Cortes Constituyentes, en uso de su soberanía, han tenido a bien nombrar Presidente del Gobierno de la República....». (Gaceta de Madrid, 15 de octubre de 1931).

${ }^{6}$ Gallego Anabitarte, A. (1971): pág. 201.

7 Desde la perspectiva actual, el significado de aquellos decretos asamblearios contrasta con el papel hoy más extendido bajo la forma de decreto. Como es bien sabido, en nuestros días, por decreto se expresan los acuerdos del Poder Ejecutivo, del Gobierno o su Presidente o —-mínimamente- algunas decisiones singulares del Jefe del Estado; y quitando su utilización para actos aplicativos de relevancia constitucional concreta — cese o nombramiento del Presidente del Gobierno y sus ministros, disolución de las Cortes, convocatoria de referéndum o la llamada al Pueblo electoral- en los aplicaciones más generalizadas sirven para el ejercicio de una potestad normativa reglamentaria, de orden secundario y subordinada a la ley parlamentaria, o incluso para emitir determinados actos resolutorios o administrativos. Un análisis de las diversas aplicaciones del decreto en nuestros días, atendiendo al contenido y eficacia de las disposiciones para las que sirve de cauce puede verse en De la Iglesia Chamarro, A. (1997). El gobierno por decreto. Pamplona.

${ }^{8}$ Santamaría Pastor, J. A. (2006). Sobre la génesis del Derecho Administrativo español en el siglo XIX (1812-1845). Iustel, Madrid, pág. 69.

9 Vid. Fernández Sarasola, I. (2009). Los primeros parlamentos modernos de España (17801823). Centro de Estudios Políticos y constitucionales. Madrid, págs. 121 y ss. Señala este autor cómo el propio calificativo que se dieron las Cortes como «Generales y Extraordinarias» es ya expresivo del carácter constituyente y soberano de las mismas. Cfr. FernándeZ SARASOLA, I. (2009): pág. 124.

${ }^{10}$ Varela Suances, J. (1987). «Rey, Corona y Monarquía en los orígenes del constitucionalismo español: 1808-1814». Revista de Estudios Políticos. Nueva época, núm. 55, págs. 126-127. 
función legislativa y las decisiones de gobierno ordinario se ejercieron por decreto asambleario.

Para entender en toda su extensión el significado de aquellos Decretos de Cortes es preciso volver la vista a los antecedentes históricos, especialmente a los inmediatos, tanto en España como en la experiencia revolucionaria francesa.

En España, en el ocaso del Antiguo Régimen, el Decreto del Rey —o de quienes ocupaban su lugar- se había convertido en el modo de exteriorización típica de las resoluciones y disposiciones del titular de la soberanía. Así, en el periodo bélico y de provisionalidad que precede inmediatamente a la reunión de las Cortes Generales y Extraordinarias en la Real Isla de León, adoptaban la forma de Decreto las principales resoluciones. De este modo, de acuerdo con las pautas del Antiguo Régimen, dictarán decretos como expresión de soberanía Carlos IV, Fernando VII, Napoleón, de José I o del Duque de Berg, etc.

El otro antecedente de gran valor lo constituyen los decretos de la Asamblea Nacional Francesa que recurrió a ellos «súbitamente» ${ }^{11}$ como modo de expresión de los principales acuerdos. La impronta de estos decretos asamblearios se puede apreciar en los Decretos de las Cortes, como se reflejará la influencia de la Constitución francesa de 1791 — también en la distinción ley-decreto- en la Constitución de 1812.

\section{EL DECRETO COMO INSTRUMENTO VINCULADO HISTÓRICAMENTE A LA POTESTAD SUPREMA}

\subsection{De los decretos a los reales decretos}

Aunque sea limitada a un fugaz recordatorio, se impone la referencia a las aplicaciones históricas del término «decreto». La expresión deriva de decretum, decernere que significa «decidir, resolver», y desde su utilización en el Derecho Romano fue expresiva de la máxima autoridad del autor y del carácter imperativo de la decisión — decretum era la decisión judicial del Emperador que ponía fin a una cuestión litigiosa ${ }^{12}$ - . A la largo de la historia, el término se utilizó profusamente en el ámbito jurídico con un sentido muy amplio. Se conservó en el ám-

11 Vid. Duguit, L. (1923). Manuel de Droit Constitutionnel. Paris, $4^{\mathrm{a}}$ ed., pág. 506.

12 Así, en el ejercicio de esa función resolutoria que lleva a la adopción de decisiones o incluso de disposiciones generales cabe citar desde el decretum del Emperador o los Decreta de los Papas o de los Concilios y decretales a los documentos que las contienen. Vid. García Gallo, A. (1984). Manual de Historia del Derecho Español. El origen y la evolución del Derecho. vol I., $9^{a}$ ed., Madrid, págs. 199-200. 
bito canónico y siguió presente con distintas aplicaciones tanto en la Edad Media como en la Edad Moderna.

En lo que aquí interesa, aparte de otras aplicaciones en los ámbitos judicial y municipal, entre nosotros — me refiero exclusivamente a la Historia de las fuentes del derecho español - se decía «decreto» al acto deliberativo y decisorio del monarca del que éste dejaba constancia marginalmente en los asuntos que eran sometidos a su consideración. Como recuerda GARCía GALlO, en la Baja Edad Media y Moderna, normalmente las disposiciones eran elaboradas por el Consejo Real que elevaba al rey una consulta con los antecedentes del caso y la propuesta de disposición; a ella respondía el rey con su resolución — sanción-, que se hacía constar en un decreto marginal sin formalidad alguna («esta es mi voluntad» o «hágase»). Después, atendiendo al contenido, se determinaba el modo de exteriorización, pudiendo redactarse en forma de Real Provisión o Real Cédula ${ }^{13}$, que eran firmadas por el rey — «promulgación- ${ }^{14}$.

Junto a las anteriores - y otras fuentes - en el siglo XVIII, con la dinastía de Borbón, se fue extendiendo y acentuando el uso del Real Decreto o Decreto Real ${ }^{15}$ y de las Reales órdenes, que indican la procedencia de la voluntad personal «del rey» —aunque estas últimas, terminarían por trasladar la voluntad de los secretarios de despacho y con el tiempo de los ministros, evolucionando así hasta las actuales órdenes ministeriales ${ }^{16}$ - . La utilización creciente del Real decreto y de la Real orden reflejaban la tendencia al reforzamiento de la posición del monarca, pues se reservaban para las disposiciones del rey sin intervención ni propuesta de los Consejos, despachadas por la vía reservada de los secretarios de despacho $^{17}$.

Puede decirse que en el siglo XVIII, los decretos, reales decretos o decretos del rey, se convirtieron en expresión generalizada para el ejercicio del poder del monarca soberano. Como dato anecdótico resulta curioso cómo por Real Decreto de 23 de octubre de 1790 el monarca ordenó al juez de imprentas el secuestro de los ejemplares de Diario de Madrid en los que se daba noticia de los hechos

13 La diferencia entre unas y otras es la mayor solemnidad de las Reales Provisiones que se dictaban en nombre del rey con mención de todos sus títulos y con requerimiento de observancia a todas las autoridades. Vid. García Gallo, A. (1984): pág. 214.

14 Ibidem. pág. 221.

15 Los primeros decretos del Rey pueden situarse en el siglo XVII, pues ya aparecen recogidos en las colecciones. Sin embargo su uso más normalizado y generalizado se produce en el siglo XVIII. Vid. De la Iglesia Chamarro, A. (1997): págs. 43 y ss.

16 Me remito al trabajo sobre esta figura y su evolución posterior de GARCía CuAdrado, A. (1986). El gobierno por orden ministerial. Eunsa. Pamplona, págs. 25 y ss.

17 García Gallo, A. (1984): pág. 214. 
acaecidos en Francia ${ }^{18}$, para evitar la entrada de las ideas revolucionarias, aunque al final, por Decreto de Cortes se acabaría proclamando la soberanía nacional (Decreto I, de 24 de septiembre de 1810).

\subsection{Los decretos por doquier en el contexto que precede a la reunión de las Cortes de Cádiz}

A finales del siglo XVIII y en el periodo histórico inmediatamente anterior a la reunión de las Cortes de Cádiz se puede vincular ya sin ninguna reserva la expresión «real decreto» al ejercicio de una potestad suprema del rey o de quien de facto la ostenta o la pretende. El decreto se ha convertido en el «tipo de disposición central y básica del sistema» ${ }^{19}$. Y así, precisamente, en este periodo de caos político, confusión y pugna por el poder, es el instrumento preferentemente para exteriorizar las principales decisiones, quedando así ligado al ejercicio de potestad suprema.

Los acontecimientos de 1808 —recuerda Artola- precipitaron la crisis del Antiguo Régimen en España y «será el año crepuscular de una España nueva, que en sus grandes rasgos continúa vigente hasta nuestros días ${ }^{20}$. La invasión francesa, las abdicaciones de Carlos IV y Fernando VII harán que surjan alternativas populares ante el vacío o inoperancia de las instituciones representativas del Antiguo Régimen. En mayo de 1808 ha comenzado ya el desmantelamiento de las instituciones políticas del Antiguo Régimen y se produce la sucesión y a veces la confluencia temporal de varios titulares de la potestad suprema. Esto se manifiesta en los modos y formas que adoptan las decisiones del poder. El decreto como exteriorización de los mandatos y disposiciones será la vestimenta formal que se dé a las decisiones principales de unos y otros, sean ejercientes o aspirantes a la soberanía. Desde 1808, la Gaceta de Madrid recoge Decretos de Carlos IV, Fernando VII, del Gran Duque de Berg ${ }^{21}$, Napole-

18 Vid. Aymes, J. R. (1989). España y la Revolución francesa. Ed. Crítica. Barcelona, págs. 118 y ss.

19 García Cuadrado, A. (1986): pág. 36.

20 Artola, M. (1975). Los orígenes de la España Contemporánea. Instituto de Estudios Políticos. $2^{\mathrm{a}}$ edición, Madrid, pág. 9.

${ }^{21}$ Así por ejemplo aquel por el que dispone las medidas para la restauración de la marina: S.A.I. y R. el Gran Duque de Berg, Lugar Teniente General del Reino, se ha servido expedir el real decreto siguiente: "considerando que el interés más urgente de España exige que se tomen las medidas más enérgicas y convenientes para acelerar la restauración de la marina (....) hemos decretado y decretamos lo que sigue: (texto articulado)... Tendréislo entendido y lo comunicaréis á quienes corresponda=En Palacio á 4 de junio de 1808=Rubricado=A D. Sebastian Piñuela», Gaceta de Madrid, 10 de junio de 1808 
ón, José $\mathrm{I}^{22}$, la Junta Central Gubernativa del Reyno o después del Consejo de Regencia ${ }^{23}$. De entre ellos, unos mostrarán una soberanía agónica y otros pretenderán el ejercicio del poder soberano de «regenerador de la patria». Al primer grupo pertenece el Real Decreto de Carlos IV abdicando la Corona en su hijo Fernando VII ${ }^{24}$ y al segundo el de Napoleón tomando el poder de la Corona de España ${ }^{25}$.

Puede concluirse de todo lo anterior que en este periodo las disposiciones jurídicas principales se dictan por decreto, como instrumento dispositivo de quien ostenta la plenitud de poder.

22 Una selección de los decretos «josefinos» más relevantes hace FERNÁNDEZ SARASOLA, I. (2006). «La primera Constitución Española: el Estatuto de Bayona». Revista de Derecho, Barranquilla, Universidad del Norte, núm. 26, pág. 109.

23 Vid. Flaquer Montequi, R. (2003), «El Ejecutivo en la revolución liberal». Artola, M. Las Cortes de Cádiz. Marcial Pons, Madrid, págs. 39 y ss.

24 «Como los achaques de que adolezco no me permiten soportar por mas tiempo el grave peso del gobierno de mis reinos, y me sea preciso para reparar mi salud gozar en clima más templado de la tranquilidad de la vida privada; he determinado, después de la mas seria deliberación, abdicar mi corona en mi heredero y mi mui caro bijo el PRINCIPE DE ASTURIAS. Por tanto es mi real voluntad que sea reconocido y obedecido como Rei y Señor natural de todos mis reinos y dominios. Y para que este mi real decreto de libre y espontánea abdicación tenga su exacto y debido cumplimiento lo comunicareis al consejo y demas á quienes corresponda. Dado en Aranjuez á 19 de marzo de 1808. = YO EL REI.=A D. Pedro Cevallos». (Gaceta de Madrid, 25 de marzo de 1808).

25 «Napoleón, Emperador de los franceses, Rei de Italia, y protector de la confederación del Rin Ec. Ec. Ec. A todos los que las presentes vieren, salud.

Españoles: después de una largada agonía, vuestra nación iba á perecer. He visto vuestros males, y voi á remediarlos. Vuestra grandeza y vuestro poder hacen parte del mio.

Vuestros Príncipes me han cedido todos sus derechos á la Corona de las Españas: Yo no quiero reinar en vuestras provincias; pero quiero adquirir derechos eternos al amor y al reconocimiento de vuestra posteridad.

Vuestra monarquía es vieja: mi misión se dirige a renovarla; mejoraré vuestras instituciones, y os haré gozar de los beneficios de una reforma, sin que experimenteis quebrantos, desórdenes ni convulsiones.

Españoles: he hecho convocar una asamblea general de las diputaciones de las provincias y de las ciudades. Yo mismo quiero saber vuestros deseos y vuestras necesidades.

Entonces depondré todos mis derechos, y colocaré vuestra gloriosa corona en las siente de otro Yo mismo, asegurándoos al mismo tiempo una constitución que concilie la santa y saludable autoridad del Soberano con las libertades y los privilegios del pueblo.

Españoles: acordados de lo que han sido vuestros padres, y mirad á lo que habeis llegado. No es vuestra la culpa, sino del mal gobierno que os regia. Tened suma esperanza y confianza en las circunstancias actuales; pues Yo quiero que mi memoria llegue hasta vuestros últimos nietos, y que exclamen: Es el regenerador de nuestra patria.

Dado en nuestro palacio imperial y real de Bayona á 25 de mayo de 1808=Firmado=Napoleón. $=$ Por el Emperador, el ministro secretado de estado Hugo B. Maret.» (Gaceta de Madrid, núm. 53, de 3 de junio de 1808).

(C) UNED. Revista de Derecho Politico

N. ${ }^{o} 83$, enero-abril 2012 


\section{LOS DECRETOS ASAMBLEARIOS \\ EN LA REVOLUCIÓN FRANCESA COMO FUENTE EXPRESIVA DE LA REVOLUCIÓN MISMA}

Como he adelantado, el otro antecedente inmediato de los revolucionarios Decretos de Cortes fueron los decretos dictados desde 1789 por la Asamblea Nacional Francesa. En el caso de estos sí puede hablarse de extraordinaria originalidad. Curiosamente, los decretos asamblearios fueron el modo de exteriorización de las decisiones más importantes de la Asamblea Nacional. Buena muestra de ello es el Décret por el que esta aprueba la Declaración de los derechos del Hombre y del Ciudadano —26 de agosto de 1789—; pero deben recordarse después los decretos de la Convención, como el célebre Décret de 21-22 de septiembre de 1792 por el que se declarara que la Monarquía queda abolida en Francia o aquel de Décret de 21 de septiembre de 1792 en el que la Convención declararía que no puede haber más Constitución que la que ha sido aceptada por el Pueblo y que las personas y las propiedades están bajo la salvaguarda de la Nación ${ }^{26}$.

Hay un dato muy curioso que conviene señalar y que distingue a las experiencias francesa y española en esta figura de los decretos asamblearios. Y es que en Francia, antes de la Revolución, los usos de la expresión décret estaban circunscritos a los ámbitos judicial y canónico ${ }^{27}$. Cuenta DUGUIT cómo el término «decreto» — de uso incierto antes de 1789_ fue súbitamente empleado entre 1789 y el año III para designar las decisiones de la Asamblea constituyente y de la Convención y, después, con el Imperio se reservó para los actos del Jefe del Estado ${ }^{28}$. Las enciclopedias ilustradas refieren para la voz «décret» un antes y un después de la revolución de 1789: «antes de 1789 no había más decretos que los de los concilios, los del Papa y algunas resoluciones judiciales que recibían ese nombre. La Asamblea Nacional lo adopta, la Convención se sirve de él

${ }^{26}$ Con texto completo, los principales decretos dictados por la Asamblea Nacional y la Convención se recogen en MARTínez ARANCón, A. (1989). La revolución francesa en sus textos. Tecnos, Madrid. También citados y con un breve extracto de su contenido en la edición castellana de TuLARd, Jean, FAyARd, J. F. y Fierro, A. (1989). Historia y Diccionario de la Revolución francesa. Cátedra, Madrid, págs. 339 y ss.

27 Así, la voz décret en el Antiguo Régimen se refiere a la sentencia por la que un juez expresa su decreto o autoridad en materia criminal y civil. También se refiere a los Decretos de la Providencia Eterna, a los Decretos del Papa, a los de los concilios y finalmente al Decreto de Graciano. Vid. Voz « décret » en Dictionnaire Universel d'Antoine Furetière. Paris, 1690 (ed. facsímil LE ROBERT, París, 1978).

28 Duguit, L. (1923), op. cit.: págs. 506. 
y el Imperio lo retoma; de forma que tenemos lo decretos de los concilios, los decretos apostólicos, los decretos de la Asamblea Nacional y los decretos del Imperio $^{29}$ ».

Esta novedad en las formas es explicable y está en sintonía con el contexto de la Revolución. Se ha dicho que la distinción entre Ancien régime y el Nouveau régime «es una separación radical sin paliativos en que quiere quebrarse toda continuidad (...) los revolucionarios querían comenzar de nuevo no sólo la historia de Francia, sino la de toda la Humanidad; incluso se cuidaron de establecer un nuevo calendario para señalar claramente la fecha desde la que Francia comenzaba de nuevo a contar su historia ${ }^{30}{ }$. Eso habría sido también trasladado al establecimiento de nuevos modos de exteriorización del poder político. En las raíces de estos decretos asamblearios no sería de extrañar que hubieran influido, como en tantos aspectos, las formulaciones de RoussEaU. Este, en su Discours sur L'Economie Politique (1755), dirá que es máxima del gobierno legítimo guiarse de la voluntad general y, que para conocerla y defender la libertad de uno sin atentar a la de los demás, la solución estriba en «imitar aquí abajo los decretos inmutables de la Divinidad $^{31}{ }^{»}$. La frase es sugerente si se pone en conexión con los elementos que inspirarán el nuevo modelo político surgido con la Revolución francesa, incluso en orden a aventurar porqué se habría recuperado desde el ámbito canónico el término «decreto» para las resoluciones principales de la Asamblea Nacional ${ }^{32}$. Por otra parte, también Rousseau en su obra El Contrato Social habría distinguido los conceptos de ley y decreto. Mientras el primero hace referencia a una regulación general, «reuniéndose en la ley la universalidad y la del objeto» ${ }^{33}$ lo que

29 Voz «décret». Grand Dictionnaire Universel du XIX siècle. Paris, 1870, vol. VI. Vid. también Gojosso, E. (1995). «Loi e décret selon Joubert en 1791». Droit prospectif. Presses Universitaires, Marsella, núm. 3, págs. 1005 y ss.

30 SÁnchez Agesta, L. (1974). Historia del constitucionalismo español. 2 a ed., Madrid, págs. 32 y 33 .

31 «Ahora bien, ¿cómo forzar a los hombres a defender la libertad de uno de ellos sin atentar contra la de los demás? (...) Por muchos sofismas con los que coloreemos todo esto, no deja de ser cierto que si se puede constreñir mi voluntad yo no soy libre y que dejo de ser dueño de mi bien desde que otro puede tocarlo. Esta dificultad, que debería parecer insuperable, fue salvada mediante la más sublime de todas las instituciones humanas o quizás mediante una inspiración celeste que le enseñó al hombre aquí abajo los decretos inmutables de la divinidad. (...). Esta referencia y el razonamiento que conduce a RousSEAU a formularla está recogido en su breve texto Discurso sobre la Economía Política. Cito la traducción de Candela, J. E. (1985).Tecnos, Madrid, pág. 14.

32 Para Carl Schmitt esta expresión de RousseAu sería una manifestación de cómo numerosos conceptos políticos derivan de conceptos teológicos secularizados. Vid. ScHMitT, C. (1934). Politische Theologie. Munich. pág. 149.

33 Rousseau, J. J. (1762). El contrato social. (Libro II, Capítulo VI «De la ley»). 
se ordena sobre un objetivo particular y concreto, sea un hombre quien lo ordena o el mismo cuerpo soberano, «eso es un decreto». Sin embargo, esta tesis de ROUSSEAU no se observó exactamente en la práctica, pues la Asamblea también dictó numerosos decretos de contenido general.

En todo caso, fuera ya del plano de las conjeturas, constituye un dato objetivo, que la Asamblea Nacional acuñó el término «Décret» con un sentido renovado y que lo empleó para designar sus decisiones principales. Después, con la Constitución de 1791 se introdujo la distinción entre décret y loi ${ }^{34}$. El primer término se utilizaba con carácter general para las resoluciones de la Asamblea cualquiera que fuera el objeto sobre el que recayeran. Ahora bien, cuando los decretos que eran votados por el cuerpo legislativo debían ser presentados a la sanción regia, entonces, devenían leyes. El texto de la Constitución de 1791 establecía que los decretos sancionados por el rey y aquellos que bubieran sido presentados en tres legislaturas consecutivas tendrían fuerza de ley y tomarian el nombre de le$y^{35}{ }^{35}$. Así, en este periodo, los decretos eran las resoluciones que la Asamblea podía adoptar por sí misma sin intervención regia; podían recaer sobre aquellas cuestiones y ámbitos decisorios reservados a la aquella ${ }^{36}$ y que escapaban al veto real $^{37}$. Como veremos, el sistema sería copiado en buena medida por los constituyentes gaditanos en 1812. En principio el criterio de distinción era el objeto: si eran disposiciones generales y abstractas debían someterse al procedimiento de sanción y publicarse como leyes. Pero, esta distinción fue más teórica que real.

Ya bajo la República, en 1793, el modelo cambió notablemente. El poder legislativo era ejercido por una Asamblea única, pero con un poder limitado por la necesidad de contar con la intervención del pueblo, que sustituye la sanción del monarca. Así, el art. 53 de la Constitución de 1793 establecía que el cuerpo legislativo adoptaba los decretos y proponía las leyes. En el caso de aquellas cuestiones que concernían exclusivamente a la Asamblea, sus resoluciones tomaban el

34 Sobre la discusión en 1789 y después 1791 acerca de qué término es más correcto para las decisiones del cuerpo legislativo si ley —que implica la participación regia— o decreto, e incluso sobre la propuesta de la expresión «ley decreto nacional». Se decía «ley» es demasiado general y el término es puramente metafísico». Sin embargo, la Asamblea constituyente utilizó sin un criterio claro las dos expresiones ley y decreto. Duguit, L. (1996), La separación de poderes y la Asamblea Nacional de 1789. Centro de Estudios Constitucionales. Madrid, págs, 31 y 32.

35 Art. 6 de la Sección III (De la sanción regia), del Capítulo III (Ejercicio del Poder Legislativo), del Título III (De los Poderes Públicos).

36 Art. 1 de la Sección I (Poderes y funciones de la Asamblea Nacional Legislativa), Cap. III, Tít. III.

37 Burdeau, G. (1984). Droit constitutionnel et instituciones politiques. LGDJ, 20 a ed., Paris, págs. 308-309. 
nombre de «Décret» y el de «Loi» se reservaba a aquellas cuestiones que debían ser sometidas al parecer popular por su carácter general o atendiendo al objeto o importancia. Se hablaba así de leyes que debían ser aceptadas por el pueblo una vez acordadas como proyecto de ley por la Asamblea ${ }^{38}$.

\section{LOS DECRETOS DE LAS CORTES DE CÁDIZ}

\subsection{Las Cortes Generales y Extraordinarias y la plenitud de poder}

Las Cortes de Cádiz se convirtieron en «la gran palanca del profundo proceso de cambio político y social», actuando como un «gobierno de asamblea» ${ }^{39}$. Siguiendo el modelo de la Asamblea Nacional Francesa, asumieron el poder en su totalidad en virtud del principio Salus populi suprema lex ${ }^{40}$ y lo ejercieron con plenitud a través de sus decretos. Ya desde su instalación, actuaron con principios y modos radicalmente nuevos, haciendo tabula rasa de la tradición jurídica española ${ }^{41}$, comenzando por la proclamación de la soberanía nacional ${ }^{42}$.

En efecto, arranca la obra legislativa y constitucional de las Cortes de Cádiz con el Decreto I, de 24 de septiembre de 1810, que determinará no sólo el papel de la Cortes, sino también los ejes de la futura Constitución ${ }^{43}$. Junto a la legítima constitución de las Cortes Generales y extraordinarias, el Decreto también proclama el principio de soberanía nacional representada por los diputados, la nulidad de la renuncia a la Corona de Fernando VII, el principio de división de poderes, la atribución a las Cortes del poder legislativo «en toda su extensión», junto a otras cuestiones. La forma rotunda del texto es bien expresiva de la cesura histórica que implica y del ejercicio radical del poder constituyente por

38 Se establecía un sistema de democracia directa para que el pueblo participara y tuviera la última palabra en el procedimiento legislativo a través de las asambleas primarias. Cfr. BURDEAU, G. (1984): pág. 311.

39 Marcuello Benedicto, J. I. (2003) «Las Cortes Generales y Extraordinarias: organización y poderes para un gobierno de Asamblea». en Artola, M. (ed.). Las Cortes de Cádiz. Marcial Pons, Madrid, pág. 67.

40 Vid. Fernández Sarasola, I. (2009): págs. 123-124. Este mismo autor refiere cómo, a pesar de la formulación del principio de división de poderes, las Cortes ejercieron un gobierno de asamblea, con poderes soberanos, especialmente durante la guerra de la independencia.

41 García Gallo, A. (1984): págs. 112-114.

42 Cfr. Diario de Sesiones de las Cortes Generales y Extraordinarias, núm. 1, 24 de septiembre de 1810

43 Torres del Moral, A. (2011). «Las Cortes según la Constitución de 1812». García EsCudero, J. A. (dir.). Cortes y Constitución de Cádiz. 200 años. Tomo III. Espasa, Madrid, págs. 3 y 4. 
parte de los Diputados que representan a la Nación española y lo ejercen con vigor $^{44}$.

En realidad, todo lo que envuelve a las Cortes Generales y Extraordinarias rebosa el ejercicio convencido de poder constituyente que se expresa en auténticos actos de soberanía ${ }^{45}$, aunque no sólo. Muestra de primero es que las Cortes se atribuirán el título de Majestad ${ }^{46}$.

Además de soberanas, las Cortes Generales y Extraordinarias hicieron una «peculiar interpretación del principio de división de poderes, que iba mucho más

${ }_{44}$ Por su interés reproduzco completo el texto del primer Decreto de las Cortes de Cádiz: «Los diputados que componen este Congreso, y que representan a la Nación española, se declaran legítimamente constituidos en Córtes generales y extraordinarias, y que reside en ellas la soberanía nacional.

Las Cortes generales y extraordinarias de Nación española (...) conforme en todo con la voluntad general, pronunciada del modo mas enérgico y patente, reconocen proclaman, y juran de nuevo por su único y legítimo Rey al Señor d. Fernando VII de Borbón; y declaran nula, de ningun valor ni efecto la cesión de la corona que se dice hecha a favor de Napoleón, no solo por la violencia que intervino en aquellos actos injustos é ilegales, sino principalmente por faltarle el consentimiento de la Nacion.

No conviniendo queden reunidos el Poder legislativo, ejecutivo y judiciario, declaran las Córtes generales y extraordinarias que se reservan el exercicio del Poder legislativo en toda su extension.

Las Cortes generales y extraordinarias declaran que las personas en quien delegaren el Poder ejecutivo, en ausencia de nuestro legítimo Rey el Señor D. Fernando VII, quedan responsables á la Nacion por el tiempo de su administracion, con arreglo á sus leyes.

Las Córtes generales y extraordinarias habilitan á los individuos que componian el Consejo de Regencia, para que baxo esta misma denominación, interinamente y hasta que las Córtes elijan el Gobierno que mas convenga, ejerzan el Poder ejecutivo.

El Consejo de Regencia, para usar de la habilitacion declarada anteriormente, reconocerá la soberanía nacional de las Córtes y jurará obediencia á las leyes y decretos que de ellas emanaren; á cuyo fin pasará, inmediatamente que se haga constar este decreto, á la sala de sesión de las Córtes, que le esperan para este acto, y se hallan en sesion permanente.» Decreto I, de 24 de Septiembre de 1808. Vid. Ed. Facsímil Colección de decretos y órdenes de las Cortes de Cádiz, Cortes Generales (1987) Madrid, vol. I, págs. 27-29.

45 Así Gallego Anabitarte refiriéndose a los Decretos de Cortes señala que era «hasta la manifestación del ejercicio de una facultad con rasgos soberanos». Vid. Gallego Anabitarte, A. (1971): pág. 172.

46 «Las Cortes Generales y Extraordinarias declaran a consecuencia del decreto de ayer 24 del corriente, que el tratamiento de las Cortes de la Nación debe ser y será de aquí en adelante el de Magestad. Las Cortes generales y extraordinarias ordenan que, durante la cautividad y ausencia de nuestro legítimo REY el Senor FERNANDO VII, el Poder Ejecutivo tenga el tratamiento de Alteza.» Este Decreto de Cortes puede leerse en la Colección de Decretos y Ordenes que han expedido las Cortes Generales y extraordinarias desde su instalación en septiembre de 1810 basta igual fecha de 1811, Tomo I, Madrid, 1820. Antes lo había hecho la Junta Central suprema y gubernativa de España e Indias constituida el 25 de septiembre de 1808 que asume el poder ante la imposibilidad de que el monarca ejerza la soberanía, antes, el pueblo, a través de las juntas supremas y soberanas. Cfr. GarCía Escudero, J. A. «Introducción. Las Cortes de Cádiz: génesis, constitución y reformas» en GarCía Escudero, J. A. (Dir.), Cortes y Constitución de Cádiz. 200 años. Tomo I, Espasa, Madrid, 2011, pág. XXI. 
allá del horizonte de la creación de un poder limitado $»^{47}$ : las Cortes legislaban, desarrollaban la legislación y dictaban resoluciones aplicativas de la misma. GALLEGO ANABITARTE se refiere a este modelo de gobierno como «Estado Legislativo» ${ }^{48}$. Todo era resuelto por las Cortes hasta el punto de constituir también de hecho el Gobierno de la Nación ${ }^{49}$. Precisamente — como señala MORÁN ORTí- el ejercicio conjunto de los tres poderes por las Cortes ${ }^{50}$ contra lo fijado en el Decreto I de 24 de septiembre fue uno de los cargos que se achacó a los diputados en $1814^{51}$.

\subsection{Los principales Decretos de las Cortes Generales y Extraordinarias. Contenido y forma}

Pues bien, esa plenitud de poder con la que las Cortes actuaron se ejerció mediante la adopción de los Decretos y Órdenes de Cortes. Los primeros se reservaron a las decisiones principales, que suponían en no pocos casos el ejercicio de un verdadero poder constituyente y desde luego legislativo y organizativo, aunque alcanzaba también cuestiones de toda índole.

En efecto, desde su constitución en septiembre de 1810 hasta 1813 las Cortes elaboraron una obra legislativa importantísima dictando centenares de decretos. De estos, muchos recogen disposiciones que atendiendo al contenido diríamos que afectan a materia constitucional: desde Decretos relativos a la afirmación de titularidad y origen del poder político o relativos a los principios esenciales conforme a los cuales este debe ejercerse; también decretos de contenido constitucional sobre facultades y papel del poder Ejecutivo o su relación con las Cortes, sobre la inviolabilidad de los diputados o de organización y ejercicio de la potestad jurisdiccional y los tribunales. También por decreto reconocieron y proclamaron derechos y libertades (imprenta, secreto de las comunicaciones,

47 Así se refiere Marcuello Benedicto al contenido de este primer decreto «Con esta declaración en que el órgano constituyente y legislativo se reservaba discrecionalmente la decisión sobre la titularidad y regulación de la forma de Gobierno, el «poder» ejecutivo no podría por menos que presentarse como una autoridad delegada y, por ende, subordinada a aquél.»Vid. MARCUELLO Benedicto, J. I. (2003): pág. 73.

48 Vid. Gallego Anabitarte, A. (1971): pág. 37.

49 MORÁN ORTí habla de «dictadura soberana» el periodo que va desde la primera reunión de las Cortes Generales y Extraordinarias hasta la aprobación de la Constitución de 1812. Cfr. MoRÁN Ortí, M. (1986). Poder y Gobierno en las Cortes de Cádiz (1810-1813). Eunsa, Pamplona, pág. 14.

50 MORÁn OrTí, M. (1984): pág. 211.

51 Una referencia detallada acerca del papel de las Cortes, las quejas del Consejo de Regencia, el Reglamento para este de 1811 puede verse en MORÁn OrTí, M. (1984): págs. 94 y ss. 
abolición de la pena de horca y de las torturas, igualdad de derechos de los españoles europeos y americanos... etc. $)^{52}$. Por Decreto de Cortes aprobaron impuestos, limitaron la extracción de dinero, o, en fin, suprimieron votos y cancelaron tribunales especiales. Puede decirse que ninguna cuestión de relevancia pública mayor o menor quedaba excluida del alcance del poder que ejercieron las Cortes por medio de sus Decretos.

En cuanto a la forma, comenzaban refiriendo a las Cortes Generales y Extraordinarias como sujeto de la decisión. A continuación incorporaban una sucinta motivación de la medida adoptada, más menos extensa dependiendo de los casos y después insertaban los artículos numerados con romanos. En otros casos la motivación y la medida aparecían en un solo texto en bloque. En el texto final del Decreto se insertaba la remisión al Consejo de Regencia, encargado de disponer todo lo necesario para el cumplimiento del decreto: «Tendrálo entendido el Consejo de Regencia para disponer todo lo necesario á su cumplimiento, y para hacerlo imprimir, publicar y circular». Y, por último, se dejaba constancia del lugar (Real Isla de León, después Cádiz ${ }^{53}$ ), fecha y firma del Presidente y dos diputados secretarios, con orden de remisión al Consejo de Regencia.

En 1810 las Cortes elaboraron un reglamento de funcionamiento para su gobierno interno y las cuestiones de procedimiento ${ }^{54}$. Se ha dicho que este primer reglamento obedeció también a una exagerada desconfianza hacia el Ejecutivo el Consejo de Regencia- de modo que el reglamento buscaba reforzar la posición de las Cortes limitando la intervención de aquel ${ }^{55}$. Lo cierto es que aquel reglamento era muy parco en su referencia a los procedimientos legislativos de las Cortes, lo que denotaba una cierta premura en la adopción y precariedad del mismo ${ }^{56}$.

En efecto, el Reglamento para el gobierno interior de las Cortes de 24 de noviembre de $1810^{57}$ dedica a las leyes y decretos de Cortes un breve y confuso artículo en Capítulo VIII, que en su apartado primero establece lo siguiente:

«las resoluciones o acuerdos que las Cortes eleven a la clase de decretos o leyes, se remitirán al Consejo de Regencia para su publicación y ejecución.»

52 Nuevamente me remito al anexo con una extensa selección de los Decretos de las Cortes más relevantes.

53 Precisamente por Decreto se dio también la orden de traslado de la Real Isla de León a Cádiz (Decreto XXXVI, de 18 de febrero de 1811).

54 Vid. Suárez Verdeguer, F.(1983): pág. 63

55 Ibidem. Pág. 27.

56 De Diego Garcia, E. (2002). «La «Orgánica» de las Cortes 1810-1813». Cuadernos de Historia Contemporánea, núm. 24, págs. 31-32.

57 Un estudio sobre este Reglamento hace Marcuello Benedicto, J. I. (2003): págs. 74 y ss. 
Puede verse que aún no hay distinción en este primer periodo entre Leyes y Decretos e incluso la fórmula de promulgación prevista es la misma y se sigue haciendo en nombre del rey:

«Don Fernando VII por la gracia de Dios, Rey de España y de las Indias, y en su ausencia y cautividad el Consejo de Regencia, autorizado interinamente, a todos lo que la presente vieren o entendieren sabed: que en las Cortes generales y extraordinarias congregadas en la Real Isla de León, se resolvió y decretó lo siguiente...»

La razón de esa falta de distinción es que las Cortes ostentan la competencia legislativa plena — «en toda su extensión»—y no se reservaban procedimientos ni intervención de otros órganos en la adopción de los acuerdos. En consecuencia, la distinción de nombres resulta en ocasiones un puro formalismo. Esto en parte viene motivado por el papel de mero auxiliar que las Cortes reconocen al Consejo de Regencia, que al no reconocérsele poder de sanción diluye la distinción formal entre ley y decreto

También se regulaba de forma muy limitada la iniciativa, la discusión o la resolución, así como las mayorías o el quórum que debía observarse para la adopción de acuerdo ${ }^{58}$. En todo caso, el Reglamento deja claro que la adopción de las decisiones de las Cortes, debía ser por votación — mayoría se entiende- que podía ser distinta en cuanto a los modos en función del objeto. Así, preveía el Capítulo VI diferentes tipos de votación de los decretos: a) por aclamación en el caso de las proposiciones a las que no se haga oposición formal y no estén comprendidas en los tres modos de votar; b) por escrutinio, para elecciones y nombramiento de todas clases; c) por acto de levantarse, para asuntos triviales y, d) por expresión individual para asuntos que se gradúen de importancia a consideración de las Cortes.

Lejos de cualquier regulación rigurosa de la reserva de procedimientos se invoca el criterio de «importancia del asunto» ${ }^{59}$. Además para la adopción de acuerdos se exigía un quórum de votos (mayoría absoluta) pero no de presencia, aunque sin distinguir los tipos de asuntos ${ }^{60}$.

Por otra parte, la intervención del Consejo de Regencia en relación con los acuerdos de las Cortes — fueran leyes o decretos - se contempla muy limitada, pues el artículo de este capítulo VIII de la remisión al Consejo de Regencia a los efectos de publicación y ejecución, pero no se habla de sanción -lo cual era propio del monarca-.

\footnotetext{
58 Vid. Marcuello Benedicto, J. I. (2003): págs. 78-81

59 Gallego Anabitarte, A. (1971): págs. 173-174.

${ }^{60}$ Ibidem, pág. 174.
} 
Las mismas Cortes, además de decretos dictaban «Ordenes de las Cortes Generales y Extraordinarias», que versaban en principio sobre temas de carácter administrativo o de orden menor. La diferencia es que si los Decretos de Cortes se expedían y firmaban por el Presidente de las Cortes, las órdenes eras firmadas por el Secretario ${ }^{61}$. En cuanto a los aspectos formales o externos, los Decretos eran publicados en la Gaceta de la Regencia de España y de las Indias. La orden de publicación se incorporaba al final del texto dirigida al Consejo de Regencia, quien promulgaba los decretos y ordenaba la publicación, según lo previsto en el Decreto de 25 de septiembre de $1810^{62}$. La fórmula promulgatoria observada era la siguiente:

«y para la debida execución y cumplimiento de los decretos precedentes, el Consejo de Regencia ordena y manda á todos los tribunales, justicias, gefes, gobernadores y demás autoridades, de cualquiera clase y dignidad, que los guarden, hagan guardar, cumplir y executar en todas sus partes. Tendreislo entendido, y dispondréis lo necesario á su cumplimiento...»

\subsection{Los Decretos de Cortes tras la aprobación de la Constitución de 1812. La distinción entre Leyes y Decretos de Cortes}

Más adelante, sobretodo a partir de la Constitución de 1812 y, después, especialmente con la aprobación del Reglamento de gobierno de las Cortes de 1813 empieza a definirse un poco más un ámbito y espacio propio para la Ley de Cortes y otro para el Decreto de Cortes ${ }^{63}$ siguiendo el esquema de la Constitución francesa de 1791.

Desde un punto de vista procedimental, lo propio de los últimos es que reflejaban un ámbito propio de las facultades de las Cortes que no requería sanción

61 La Orden servía para decisiones de menor importancia, y no requería la solemnidad del decreto. Vid. García Cuadrado, A. (1986): pág. 38

${ }^{6}$ Colección de Decretos y Ordenes de las Cortes Generales y Extraordinarias, Imprenta Nacional, Madrid, 1820. Esta obligación de promulgación del Consejo de Regencia se recogió más tarde en el Reglamento provisional del Consejo de Regencia: «El Consejo de Regencia hará se lleven a efecto las leyes y decretos de las Cortes, para lo cual los publicará y circulará en la forma prevenida en el decreto de 25 de septiembre de 1808. Los decretos del Poder legislativo, autorizados por el Presidente y los dos Secretarios, se remitirán al Consejo de Regencia por un mensagero de las Cortes y un alabardero. El Consejo de Regencia avisará por medio de un alabardero y un mensagero haber recibido el decreto, y quedar encargado de su ejecución....»

63 Pero hasta el Reglamento de 1 de junio de 1821 dictado en el Trienio liberal no se establecerá con minuciosidad en qué casos las disposiciones debían ser objeto de ley o de decreto. Vid. Gallego Anabitarte, A. (1971): págs. 190 y ss. 
regia. A diferencia de estos, tendrían carácter de ley aquellos Decretos de Cortes que, atendiendo a su importancia, su perpetuidad u orientación al bien común debían sancionarse como ley y, en consecuencia, debían ser sancionados por el monarca $^{64}$. La influencia de la distinción formulada por ROUSSEAU entre ley y decreto $^{65}$ puede apreciarse en esta regulación de la Constitución de 1812 —al menos en un plano teórico-.

En efecto, el art. 15 de la Constitución de 1812 establecía que «la potestad de hacer leyes reside en las Cortes con el Rey». Por su parte, el art. 131, al enumerar las facultades de las Cortes, les atribuía, en primer lugar la de «proponer y decretar las leyes» y más adelante señalaba que al Rey correspondía «la sanción de las leyes» (art. 143). La sanción del monarca era una «sanción necesaria» ${ }^{66}$ y, en su caso, el veto tenía un efecto puramente dilatorio.

Sin duda, más allá de la distinción formal, la cuestión más interesante que empieza a apuntarse en este periodo es la delimitación del objeto de lo que ha de ser ley o decreto. No hay duda de que serán Decretos de Cortes las resoluciones que estas adopten en el ejercicio de las competencias del art. 131 de la Constitución de 1812, muchas de primer orden: resolución de dudas sobre cuestiones sucesorias en relación con la Familia Real, nombramiento de Regente, tutor, cuestiones de política exterior, adopción de tratados, fijación de tropas para la defensa militar, cuestiones de carácter económico y financiero - ingresos, gastos, tributos - y otras, en el art. 384 para la acordar la reforma de la Constitución. Sin embargo ¿cuándo debe aprobarse como ley? ${ }^{67}$.

Como se ve es indudable la influencia que en este punto tuvo la Constitución francesa de 1791, aunque las funciones de las Cortes de Cádiz previstas en el art. 131 de la Constitución de 1812 como competencia exclusiva eran mucho más

64 Ibidem, p. 121.

65 Gallego Anabitarte se muestra crítico con este planteamiento de Rousseau que sitúa a la ley exclusivamente en el plano de la generalidad y abstracción, mientras que el decreto carecería por definición de tal generalidad y sería un acto concreto de soberanía o de magistratura: «es una distinción carente de sentido político y jurídico, como todo lo que centra su atención en criterios formales y logicistas». Para este autor, en la tesis rousseauniana puede verse el origen teórico de la distinción ley (general), Decreto-reglamento (acto de concreción de la ley). Cfr. GALLEGo ANABITARTE, A. (1971): págs. 129-132.

${ }^{66}$ El significado de la sanción regia fue objeto de discusión y la parte más polémica del procedimiento legislativo. No en vano el significado de la sanción es lo que determinaba el modo de repartirse las funciones principales entre el Monarca y las Cortes. Vid. VArela SuAnces, J. (1987): págs. 157-161.

67 El final de este periodo de actividad de las Cortes con la llegada de Fernando VII cortó de plano esta cuestión de calado que, sin embargo, se reavivó en el trienio liberal. De ella da cuenta Gallego Anabitarte, A. (1971): págs. 190 y ss. 
amplias que las que estaban exentas de la intervención regia en la Constitución francesa de $1791^{68}$.

El Reglamento de 1813 recogió no sólo la distinción Ley-Decreto sino que, de acuerdo con los procedimientos, permite distinguir varios tipos de Decretos de Cortes. El Capítulo X del Reglamento se dedica a «De los Decretos». Y se refiere a los decretos con carácter de ley, que deben después presentarse a la sanción regia. Estos decretos habían de extenderse de la forma siguiente: «Las Cortes, después de haber observado todas las formalidades prescritas por la Constitución, han decretado lo siguiente (aquí se pondrán los artículos aprobados), lo cual presentan las Cortes a S.M. para que tenga a bien dar su sanción (aqui la fecha y las firmas de presidente y de dos de los se(retarios)»—art. CIX—. El Reglamento preveía también que en caso de minoría de edad del Rey o imposibilidad, que las Cortes no sometieran los decretos para ser leyes, —en su caso a sanción de la Regencia. Para ese caso, el decretoque sería ley —en la fórmula promulgatoria debía prever las variaciones requeridas (art. CXII)—.

Pero además de estos Decretos que tomaban el nombre de Leyes, el Reglamento recogía otros tres tipos de Decretos de Cortes ${ }^{69}$ :

a) sobre asuntos propuestos por el Rey. Estos tenían su fórmula promulgatoria particular ${ }^{70}$ (art. CIX)

b) aquellos decretos por los que las Cortes dieran consentimiento al Rey sobre cuestiones previstas en la Constitución (art. CX) en relación con el art. 131 de la Constitución de 1912.

c) o, finalmente, aquellos decretos de las Cortes sobre asuntos en los que no se requiere ni propuesta del Rey, ni su sanción (art. CXI ${ }^{71}$. Estos Decretos de Cortes, habían de remitirse al Rey por el conducto del respectivo secretario del Despacho.

Toda esta obra legislativa y regulación e incipiente distinción de procedimientos legislativos que empieza a ordenar el recurso a aquellos improvisados

68 Vid. Gallego Anabitarte, A. (1971): pág. 160.

69 Se refiere a estas tres modalidades como Decretos de aprobación, de dar consentimiento y propios Gallego Anabitarte, A. (1971): págs. 177-178.

70 «Las Cortes habiendo examinado la propuesta de S.M. sobre (aquí la propuesta del Rey) han aprobado (aquí se pondrá lo que se haya resuelto), y concluirá con la fecha y las firmas del presidente y de dos de los secretarios. El Rey lo publicará con la fórmula siguiente. N. Por la gracia de Dios, y por la Constitución de la monarquía española, Rey de las España, a todos los que las presentes vieren y entendieren, sabed: Que habiendo Nos propuesto a las Cortes (aquí el texto), las Cortes lo han aprobado, y por tanto mandamos (etcétera).»

71 En estos casos, la fórmula prevista era la siguiente: «Las Cortes usando de la facultad que se les concede por la Constitución, han decretado (aquí el texto), y se concluirá con la fecha y las firmas del presidente $y$ de dos secretarios. » 
Decretos de las Cortes Generales y Extraordinarias quedará en suspenso o, en algunos casos, tendrá su punto final en 1814. Los Decretos de Cortes reaparecieron en el Trienio Liberal (1820-1823), en 1836-37 y, excepcionalmente, tienen alguna manifestación en la II República española ${ }^{72}$. Sin embargo, es preciso subrayar que, si bien en parte la ley en sentido formal ha venido a sustituirlos, aquellos decretos asamblearios de las Cortes Generales y Extraordinarias fueron expresión de la revolución misma y reflejaron —aunque fuera provisionalmente y por poco tiempo- la transferencia de la soberanía a la Nación representada en las Cortes.

72 En 1931 las Cortes Constituyentes de la II República nombraron por Decreto de Cortes al Presidente del Gobierno ante la ausencia de titular de la Jefatura del Estado: «Las Cortes Constituyentes, en uso de su soberanía, han tenido a bien nombrar Presidente del Gobierno de la República....». (Gaceta de Madrid, 15 de octubre de 1931). El dato es curioso, porque en no pocos aspectos las Cortes Constituyentes de 1931 adoptaron el modelo de parlamentario unicameral, como lo hicieran la Asamblea Nacional Francesa o las propias Cortes de Cádiz. Vid. De la Iglesia Chamarro, A. (1997): págs. 94 y 95. 


\section{ANEXO \\ Selección de Decretos de las Cortes Generales y Extraordinarias (1808-1813)}

- Decreto I, de 24 de septiembre de 1810: Declaración de la legítima constitución de las Cortes y de su soberanía: nuevo reconocimiento del Rey Don Fernando VII, y anulación de su renuncia a la Corona: división de Poderes, reservándose las Cortes el legislativo: responsabilidad del ejecutivo, y habilitación de la Regencia actual, con la obligación de prestar juramento a las Cortes; fórmula de este: confirmación interina de los tribunales, justicias y demás autoridades: inviolabilidad de los diputados.

- Decreto II, de 25 de septiembre de 1810: Tratamiento que deben tener los tres Poderes: fórmula con la que el ejecutivo debe publicar las leyes y decretos que emanen de las Cortes: se prescribe el juramento a todas las autoridades.

- Decreto IV, de 27 de septiembre de 1810: Declaración de las facultades y responsabilidad del Poder ejecutivo, y del modo con que este debe comunicarse con las Cortes, en consecuencia de las dudas que el Consejo de Regencia expuso a las mismas.

- Decreto V, de 15 de octubre de 1810: Igualdad de derechos entre los españoles europeos y ultramarinos.

- Decreto VI, de 28 de octubre de 1810: Nombramiento del nuevo Consejo de Regencia.

- Decreto IX de 10 de noviembre de 1810: Libertad política de imprenta.

- Decreto XIII, de 28 de noviembre de 1810: Confirmación de la inviolabilidad de los diputados a Cortes.

- Decreto XIX, de 1 de enero de 1811: declarándose nulos todos los actos y convenios del Rey durante su opresión fuera o dentro de España.

- Decreto XX, de 5 de enero de 1811: se prohíben las vejaciones hechas aquí a los indios primitivos.

- Decreto XXII, de 15 de enero de 1811: se prohíbe la apertura general de cartas.

- Decreto XXIV, de 16 de enero de 1811: Reglamento provisional del Poder Ejecutivo.

- Decreto XXXI, de 9 de febrero de 1811: se declaran algunos de los derechos de los Americanos.

- Decreto LXI, de 22 de abril de 1811: de abolición de la tortura y de los apremios, y prohibición de otras prácticas aflictivas. 
- Decreto LXII, de 2 de mayo de 1811: Aniversario perpetuo del día 2 de Mayo por los primeros mártires de la libertad nacional.

- Decreto LXXVI, de 14 de julio de 1811: responsabilidad de las autoridades en el cumplimiento de las órdenes superiores.

- Decreto LXXXII, de 6 de agosto de 1811: Incorporación de los señoríos jurisdiccionales a la Nación.

- Decreto CVII, de 11 de noviembre de 1811: De la responsabilidad sobre la observancia de los decretos del Congreso nacional.

- Decreto CXXV, de 22 de enero de 1812, creación de la Regencia del Reino.

- Decreto CXXVIII, de 24 de enero de 1812: Abolición de la pena de horca.

- Decreto CXXIX, de 26 de enero de 1812: Nuevo reglamento de la Regencia del Reino

- Decreto CXXXVII, de 14 de marzo de 1812: solemnidades con que se manda firmar, jurar y publicar en Cádiz la Constitución Política de la Monarquía española.

- Decreto CXLII, de 18 de marzo de 1812, exclusión de algunas personas reales de la sucesión a la Corona de las Españas.

- Decreto CLXI, de 22 de mayo de 1812, que el clero y el pueblo presten juramento a la Constitución a un mismo tiempo y sin preferencia,

- Decreto CLXV, de 25 de mayo de 1812: Indulto general con motivo de haberse publicado la Constitución de la Monarquía.

- Decreto CLXIX, de 8 de junio de 1812: Reglamento del Consejo de Estado.

- Decreto CLXXIII de 13 de junio de 1812: se prohíbe la libre extracción de numerario.

- Decreto CLXXIX, de 10 de julio de 1812: Reglas sobre la formación de los Ayuntamientos constitucionales.

- Decreto CLXXX, de 20 de julio de 1812: Cómo debe el Supremo Tribunal de Justicia expedir su ejecutorias y provisiones.

- Decreto CLXXXV, de 14 de agosto de 1812: que se llame Plaza de la Constitución la principal de los pueblos en que esta se publique.

- Decreto CXCIII, de 21 de septiembre de 1812: Los eclesiásticos seculares tienen voto en las elecciones de los ayuntamientos, pero no pueden obtener en ellos ningún oficio.

- Decreto CXCVI, de 25 de septiembre de 1812: Don Juan Pérez Villamil es nombrado Regente del Reino.

- Decreto CXCVIII, de 7 de octubre de 1812: Que los alcaldes constitucionales de los lugares que fueron de señorío ejerzan la jurisdicción civil y criminal. 
- Decreto CCV, de 5 de noviembre de 1812: Sobre los límites de las Jurisdicciones eclesiásticas castrense y ordinaria.

- Decreto CCXXXIII, de 22 de febrero de 1813: Abolición de la Inquisición: establecimiento de los tribunales protectores de la Fe.

- Decreto CCXLVII, de 8 de abril de 1813: Nuevo Reglamento de la Regencia del Reino.

- Decreto CCLXII, de 8 de junio de 1813, sobre el libre establecimiento de fábricas y ejercicio de cualquier industria útil.

- Decreto CCLXIII, de 10 de junio de 1813: Adiciones a la ley de libertad de imprenta.

- Decreto CCLXIV, de 10 de junio de 1813: Reglamento de las juntas de censura.

- Decreto CCLXV, de 10 de junio de 1813: Reglas para conservar a los escritores la propiedad de sus obras.

- Decreto CCLXXXIV, de 17 de agosto de 1813: Prohibición de la corrección de azotes en las escuelas, colegios, etc.

- Decreto CCXCIII, de 4 de septiembre de 1813: Reglamento para el Gobierno interior de las Cortes.

- Decreto CCXCIX, de 8 de septiembre de 1813, Abolición de la pena de azotes: se prohíbe usar de este y otros castigos con los indios 
Title:

THE CADIZ PARLIAMENTARY REVOLUTION THROUGHT ITS ASSEMBLY DECREES

\section{Summary:}

1. Preliminary considerations. 2. The decree like tie instrument historically to the supreme power. 2.1. Of the rights to real decrees. 2.2. The decrees everywhere in the context that precedes to the meeting of Courts of Cadiz. 3. The assembly decrees in the French Revolution like expressive source of the same revolution. 4 . The decrees of Cortes of Cadiz. 4.1. General and Extraordinary Cortes and the fullness of being able. 4.2. The main Decrees of General and Extraordinary Courts. Content and forms. 4.3. The Decrees of Courts after the approval of the Constitution of 1812. The distinction between Laws and Decrees of Courts.

\section{Resumen:}

Las Cortes Generales y Extraordinarias de Cádiz (1810-1813) ejercieron su plenitud de poder a través de una figura original y revolucionaria: el Decreto de Cortes. Esta figura — que cuenta con el antecedente de los decretos asamblearios en la Revolución Francesa de 1789- sirvió para poner las primera piedras del moderno Estado Constitucional. Y así, por Decreto de Cortes se afirmarán, entre otros elementos que le son propios, la soberanía nacional, la división de poderes o la libertad de imprenta, aunque, como es bien sabido, el intento constitucional de Cádiz quedó varado en 1814 cuando — también por Decreto- el rey Fernando VII derogó la Constitución de 1812.

Históricamente, en España, la figura del Decreto o venía ligada al ejercicio de la soberanía del monarca. Por eso, los Decretos de Cortes, en sí mismos, son expresivos de la revolución misma en la medida en que reflejan la transferencia de la soberanía del rey a la Nación.

Las Cortes establecieron de facto un sistema de gobierno asambleario y llevaron a cabo su obra principalmente a través de Decretos (más de trescientos), unos de contenido constitucional, otros de carácter legislativo y otros, en fin, de ordinario gobierno.

En 1812, comienza a perfilarse una distinción entre Decreto (de exclusiva competencia de las Cortes) y Ley (cuando atendiendo al objeto regulación de carácter general y abstracto- aquel debe recibir sanción regia). Esta distinción es tributaria del constitucionalismo francés que, a su vez, en este punto, acoge la tesis de Rousseau, que en su obra el Contrato Social distingue entre ley (disposición general y abstracta) y decreto (acto o resolución particular, aunque sea expresión de soberanía). 


\begin{abstract}
:
The General and Extraordinary Parliament of Cádiz (1810-1813) exercised its full power through an original and revolutionary legal instrument: the Assembly Decree. This legal instrument, which evolved from the assembly-decrees of the French Revolution of 1789, ultimately served as a cornerstone of the modern Spanish constitutional state. In this way, the Assembly Decrees, affirm, amongst many other elements, questions of national sovereignty, the separation of powers and the freedom of the press.

In Spain, the legal form of the Decree or Royal Decree historically evolved from an exercise of the sovereignty of the monarch who, through these royal decrees, expressed his personal decisions.

It is for this reason that, the Parliamentary Decrees are, in themselves, expressive of the revolution itself, insofar as they reflect the transfer of sovereignty from the king to the nation, and through them establish the constitutional cornerstones of our national history.
\end{abstract}

\title{
Palabras clave:
}

Decretos de Cortes, soberanía, ley, división de poderes, Cortes de Cádiz.

\section{Key words:}

Decrees of Parliament, sovereignty, law, separation of powers, Cortes de Cádiz 